\title{
Strategies to Promote Meaningful Student Engagement in Online Settings
}

\author{
Glennda K. McKeithan ${ }^{1}$, Mabel O. Rivera ${ }^{2}$, Lara E. Mann ${ }^{3}$, Lisa B. Mann ${ }^{1}$ \\ ${ }^{1}$ Department of Special Education, University of Kansas, Kansas, United States \\ ${ }^{2}$ School of Educational Leadership \& Specialties, University of North Carolina Pembroke, North Carolina United States \\ ${ }^{3}$ Department of Education, Aurora University, Illinois, United States \\ Correspondence: Glennda K. McKeithan, Department of Educational Leadership and Specialties, 1122 W. Campus Road, \\ JRP, Lawrence KS, 66045, United States.
}

Received: January 23, 2021

doi:10.11114/jets.v9i4.5135
Accepted: March 9, $2021 \quad$ Online Published: March 14, 2021

URL: https://doi.org/10.11114/jets.v9i4.5135

\begin{abstract}
Distance learning or online education has increased significantly over the past decade to coincide with easy access to technology and the availability of multifaceted learning management system software that can be used to develop asynchronous educational experiences (Ginder et al., 2018). The increased demand for online education, as well as unprecedented circumstances (Covid-19 Pandemic) that require quick changes to instructional delivery alternatives, have resulted in many traditional face-to-face programs transitioning into online and hybrid (e.g., part online and part face-toface) programs across curriculum content areas to attract and retain full and part-time learners (DuPont et al., 2018). Effective online instruction must be engaging and meaningful/relevant. Course authors and instructors in higher education must incorporate strategies to maximize student engagement to develop high-quality learning experiences in online environments (Fallahi, 2019; Weidlich \& Bastiaens, 2018). This article discusses the application of varied strategies and instructional practices to help instructors in post-secondary educational settings enhance the quality of teaching and social presence in the online learning environment. The strategies addressed are connected to the teachers' ability to integrate multifaceted learning goals into instructional planning and delivery in order to create effective online learning environments that may improve outcomes for students across settings and content areas (Dixson, 2015; Henrie et al., 2015; Moore \& Shemberger, 2019).
\end{abstract}

Keywords: distance education, online learning, social presence, teaching presence, student engagement, instructional strategies, teacher behaviors

\section{Introduction}

\subsection{Introduce the Problem}

Online instruction is an unparalleled revolution, perfect for today's digital citizenry and demands, for which enrollment has grown exponentially over the past decade with at least one-third of college students now enrolled in one or more online classes (Ginder et al., 2018). Online learning provides educational experiences to traditional and non-traditional students managing multiple responsibilities with busy schedules as well as those in rural and developing communities. Students of lower socioeconomic status and/or living in rural communities can access learning programs using technology which is more readily available without being hampered by distance from the institution or instructor. In a world where social distancing is a relevant factor and time zone and physical distance are no longer relevant, the online classroom is a global possibility for learners seeking to learn new skills and advance career opportunities (Wynants \& Dennis, 2018).

\subsection{Importance of the Problem}

To remain relevant and successful, traditional face-to-face programs in many institutions of higher education (IHEs) must now compete for students with easy access to online programs that offer flexible programming for learners who may be attracted to the limited synchronous (real time learning; simultaneous instruction) and asynchronous (not real time; students access content on their own - within given time constraints) nature of online instruction. Unfortunately, high caliber instruction and faculty expertise in online learning experiences may vary significantly and become a potential negative impact on quality. The challenge for IHEs is to design and deliver relevant, engaging educational experiences that meet learner needs given that student attrition in remote learning is higher than traditional settings (Croxton, 2014; Lowenthal \& Hodges, 2015). 


\subsection{Describe Relevant Scholarship}

The literature suggests that college students who, in the past, had selected face-to-face sections mostly for the immediacy to the instructor and personal time management issues may not have that choice now and must learn to adapt organizational and time management skills to this new reality (Aronson, 2020). Consequently, faculty must utilize the tools and strategies needed to create engaging and supportive learning experiences. Course authors and instructors who plan and deliver instruction must be mindful of the realities of transactional distance and purposefully integrate strategies into the learning environment to promote active student engagement. The literature also supports the need to minimize the transactional distance between faculty and students along with maximizing instructor immediacy can positively impact achievement (Al-Ghamdi, 2017). In addition, programs must offer resources and supports to students who may not be knowledgeable or confident using new programs and advanced technology. The COVID-19 pandemic, for example, has challenged educational settings to create K-20 virtual learning communities practically overnight assuming that both faculty and students have the necessary skills and equipment to be successful. College students who, in the past, had selected face-to-face sections mostly for the immediacy to the instructor and personal time management issues may not have that choice now and must learn to adapt organizational and time management skills to this new reality (Aronson, 2020). Consequently, faculty must utilize the tools and strategies needed to create engaging and supportive learning experiences. Course authors and instructors who plan and deliver instruction must be mindful of the realities of transactional distance and purposefully integrate strategies into the learning environment to promote active student engagement.

\section{Methods}

\subsection{Transactional Distance}

Transactional distance is the psychological and communication gap that results from the physical separation between students and peers (social presence), students and instructors (instructor presence), and students and content in online classrooms (Koslow \& Pina, 2015; Stopa, 2017). Designing learning experiences which effectively negotiate transactional distance can differentiate a low-quality learning from an inspirational learning experience (Best \& Conceição, 2017). Developing quality online learning must include strategies to enhance social and instructor presence to help learners meaningfully access content and meet desired learning goals. Institutions of higher education must provide distance education that maximizes student engagement to minimize attrition, improve student satisfaction, enhance motivation to learn, and increase student performance (Dixson, 2015). Several online platforms offer updated features that support live and synchronous online meetings--which, whether whole or small groups, can contribute (in real time) to minimize physical distance in online courses and improve collaboration and active participation. Most strategies noted in this article can be used with both synchronous and asynchronous learning environments.

\subsection{Student Engagement}

Student engagement - that attention, curiosity, interest, optimism, and passion students show when learning - is relatively simple to determine in a traditional face-to-face class. Students demonstrate engagement when they are focused on the presentation, actively listening, nodding, and taking notes. Distractions can be minimized by asking students to put away phones and laptops, close the window, and save side-conversations for a break. In this traditional format, the instructor presents the lecture, leads the discussion, and answers questions. Students can build a rapport with the instructor and other students in the class through repeated class meeting times, discussions, group projects, etc. Engagement in face-to-face classes has been observed for millennia of organized education (Henrie et al., 2015). A perennial problem in online education is student engagement-how to know if it is happening, how to measure it, and how to improve it. When students are engaged and motivated, they show higher rates of retention in online programs and steady enrollment. Engagement and motivation are crucial for student success in the online classroom and overall achievement. Without the built-in social support of the traditional classroom, such as an in-person community of peers interested in the same topic, course authors and instructors must be more strategic about how they ask students to engage with the material and with each other (Reese, 2015).

Actively engaging students in online instruction can be a challenge. Instructors may not have experienced online instruction as a student, and they may have limited understanding of factors associated with positive online learning experiences (Bledsoe \& Simmerok, 2013; Kuo et al., 2014). Online instructors must grow and develop as learners themselves as well as in reflective practice to meet the evolving needs of students (Reese, 2015). Often, asynchronous online courses are designed in advance of the course launch to allow students the flexibility of completing tasks at their own pace. However, this can result in students essentially teaching themselves content and working through activities and assignments on their own. Limited interactions with others can become an unfortunate characteristic of online instruction, and this social isolation can inhibit motivation and student satisfaction (Yilmaz \& Keser, 2017). Fortunately, such potential downfalls can be avoided. Online learning can provide an active social presence that encourages meaningful interactions 
with the content as well as peers via active discussions, cooperative learning opportunities, group conferences, problembased learning, and simulations which require students to apply new learning in real-life settings (Weidlich \& Bastiaens, 2018).

Actively engaged students are more motivated and likely to seek assistance when needed. Effective and meaningful teacher and peer interactions are needed to promote engagement, satisfaction, and establishment of meaningful learning communities for learners (Moore \& Shemberger, 2019; Sammel et al., 2014). The frequency and methods used to promote quality engagement via a strong teaching presence (teacher/student interaction) as well as a meaningful social presence (student/student interaction) can vary significantly between programs and course sections.

\subsection{Content Organization}

Online courses must be extensively planned from the learner's perspective. When asked to author an online course, faculty may be tempted to cut and paste materials from their face-to-face lectures; however, a total course redesign, using the backward planning method, can result in a much higher quality online class (Black \& Allen, 2019). Instructors must consider the course objectives, transactional distancing concerns and design the course with clear, realistic learning goals answering the basic "W questions." For example, Who are the learners? Why is the course content important and relevant to their current or future experiences? What prior knowledge and misconceptions about content might they have at the beginning of the course? What are the likely time constraints and abilities which could adversely affect their progress? What are the potential technology-related barriers to student success? What resources are available for students to address any potential concerns?

Consider developing content around key constructs (primary learning objectives) into learning modules with clear goals and objectives. Ensure that learners recognize how information and activities in each module are connected to short- and longterm learning goals. Instructors can make learning goals more meaningful by connecting them to professional standards and evidence-based practices in the field. Faculty may consider providing a routine in the sequence of learning activities to help learners establish study and participation guidelines within their own schedules as they progress through given units (or modules). For example, all modules might start with an overview of objectives and learning goals, proceed onto a presentation about the module theme, followed by supplemental readings, discussion, assignment, quiz and wrap up.

Presentations, whether narrated videos or text-based-- consider offering both learning modalities-- can help learners to progress from one construct to another taking into account potential prior knowledge, relevance, and how each idea may build or develop later in the current course, future courses or in real-life application. Be careful not to overwhelm learners with too much content at once. Consider chunking key constructs into smaller subtopics. A common downfall in online course design is to insert video lectures of 30,45 , or even 60 minutes in length; research supports that lectures should consider the 10 to $15 \mathrm{~min}$ attention span that frequently represents modern students (Svinicki \& McKeachie, 2013). Instructors can use a variety of supports to help students task analyze, prioritize, attend to tasks, initiate and focus on meeting specific expectations. Integrate visuals, short video clips, etc. into presentations to help learners digest concepts and identify how to apply content to their own experiences.

\subsection{Metacognitive Strategies}

Do not assume students have the background knowledge, metacognitive and problem-solving skills needed to complete tasks. Teach tasks, provide links to needed resources, use repetition and be willing to step in and help as needed. Support content with current research when possible and model how to present informed knowledge (rather than opinion) to students by using correctly formatted parenthetical citations and references in presentations. Create a citation for each module presentation so students can accurately site presentation content in their own assignments. Be familiar with course readings and be sure module presentations do not mirror content from readings.

Modules should include materials and activities that directly support the learning goals and objectives. Engage the learner through interaction with content by requiring them to use information from presentations and readings in assignments as well as in communication with others. Support the development of professional communication of informed knowledge rather than informal opinion or supported opinion. Help students understand the benefit of developing communication skills that are mindful and respectful of different perspectives and simultaneously objective, professional, and supported by sound research. Provide the resources (examples/non-examples) students need to readily apply these skills into assignments and hold them accountable by making these expectations part of the assessment process when applicable. When possible, design the sequence of learning activities using logic and linear structure so learners can easily understand where to start and how to progress through each module. In order to make sure all course objectives are met; course maps can be created to organize the content. Task-analyze each component of the course to clarify which constructs should be taught directly, which assignments students are responsible for producing, and how much time each activity will require of students. Table 1 provides an example of a course map that can be used when developing courses. 
Table 1. Online Course Mapping Considerations

\begin{tabular}{|c|c|c|c|c|c|c|}
\hline Wk. & Unit & Outline & $\begin{array}{l}\text { Lecture } \\
\text { Materials }\end{array}$ & Readings & Discussion & Assessment \\
\hline $1-2$ & $\begin{array}{l}\text { Unit } \\
\text { Content } \\
\text { or } \\
\text { Theme }\end{array}$ & $\begin{array}{l}\text { Overview of } \\
\text { content: } \\
\text { Activities, } \\
\text { estimated time } \\
\text { demand for } \\
\text { each activity; } \\
\text { connection to } \\
\text { relevant } \\
\text { objectives } \\
\text { (school, } \\
\text { program or } \\
\text { national); and/or } \\
\text { connection to } \\
\text { professional } \\
\text { standards }\end{array}$ & $\begin{array}{l}\text { PowerPoint, } \\
\text { Audio Lecture, } \\
\text { Narrated } \\
\text { PowerPoint, } \\
\text { etc.; adhere to } \\
\text { accessibility } \\
\text { guidelines, } \\
\text { avoid just } \\
\text { reading the } \\
\text { slides, add } \\
\text { insight into the } \\
\text { materials } \\
\text { covered to } \\
\text { supplement the } \\
\text { unit content }\end{array}$ & $\begin{array}{l}\text { APA citation, } \\
\text { link to articles, } \\
\text { do not repeat } \\
\text { information in } \\
\text { the lecture, } \\
\text { connect to } \\
\text { assessment } \\
\text { methods; allow } \\
4 \text { min per page } \\
\text { for challenging } \\
\text { reading content; } \\
\text { use current } \\
\text { readings (5-7 } \\
\text { year range) }\end{array}$ & $\begin{array}{l}\text { Small groups, } \\
\text { varied, multiple } \\
\text { prompts to } \\
\text { select from, } \\
\text { relate to } \\
\text { content, rotate } \\
\text { groups, specific } \\
\text { expectations, } \\
\text { consider online } \\
\text { discussion } \\
\text { forum as well } \\
\text { as video } \\
\text { discussions } \\
\text { with or without } \\
\text { instructor }\end{array}$ & $\begin{array}{l}\text { Quizzes, } \\
\text { assignments, } \\
\text { projects, be } \\
\text { specific and } \\
\text { mindful of } \\
\text { timelines, task } \\
\text { analyze for } \\
\text { students, link to } \\
\text { objective grade } \\
\text { rubric }\end{array}$ \\
\hline
\end{tabular}

Basic organizational strategies are outlined in Table 2 - syllabus requirements, module content, grading policies, units of modules with estimated time limits, specific goals, required assignment policy, department grading policies, connection to professional standards, etc. (Vlachopoulos \& Makri, 2019).

Table 2. Recommended Syllabus Components for Online Classes

- Course name and description

- $\quad$ Align description with course program manual

- Link to professional certification (clarify if the course linked to professional certification)

- Instructor information (how and when to contact)

- Alternative resources

- School writing center

- School technology resources

- Student support counselors (if appropriate)

- $\quad$ Required materials

- Clarify if students will need materials for extended time to help them make decisions when renting texts

- Suggest multiple sources to purchase materials (bookstore, publisher, etc.)

- Estimated weekly time demand (readings, assignments, assessments, discussion, etc.)

- $\quad$ Grade policy (are there required assignments, can students choose to omit an assignment, etc.)

- Course progression policy - clarify minimum grade needed to earn credit for the class

$\circ \quad$ Late policy - be specific (when to contact you; consider requiring students to suggest alternative submission date)

- Use technology to auto calculate point loss; motivate students to submit ontime

- Incomplete policy

- Clarify school/department policy (expectations/requirements/procedures/due dates)

- Overview of course content (types of assignments, categories, etc.)

- Student support information (troubleshooting, reminder to check school email \& announcements, link to university calendar related to add/drop, etc.)

- Writing expectations and connection to style guidelines

- Connection to professional standards, etc. 
Developing an introductory module can also help learners navigate their way through the course by walking students through important information in the syllabus. Include a short (not too intimidating) instructor biography and review expectations for scholarly writing, etiquette in the online classroom, and key factors associated with learner progress within the program. Point out unique grade expectations such as minimum grade requirements to pass the course, required assignments, etc. to clarify expectations for students. To maximize the potential that students will take the time to review course "housekeeping" chores, require students to read the introductory unit and complete a check for knowledge of pertinent information with a graded scavenger hunt.

\subsection{Accessibility}

For students to engage with course content, they must be able to fully access it. In the online learning environment, "accessibility" means that individuals with and without disabilities can equally perceive, understand, navigate, interact with, and contribute to a website (World Wide Web Consortium, 2019). Institutions that receive federal funding are required to make their Web and non-Web content (e.g., downloadable Word and PDF documents) accessible under Section 508 of the Rehabilitation Act of 1973, as revised in the Information and Communication Technology (ICT) Standards and Guidelines (Board, 2017). The content is required to meet Web Content Accessibility Guidelines (WCAG) 2.0 developed by the World Wide Web Consortium (W3C). The WCAG 2.0 guidelines are extensive, and many address issues best left to Instructional Designers (IDs) rather than teaching faculty. However, even when IDs set up courses and modules in a learning management system (LMS) to meet all criteria, it is not unusual for course authors or instructors to "go rogue," adding personal touches and additional materials to the course pages - sometimes to the detriment of accessibility (Linder, Fontaine-Rainen, \& Behling, 2015). Course authors may forget that what they see on their computer screen may not be what their student sees. For example, a student may be color blind or have another visual impairment, may use "high contrast mode" on their display, or may view the page in bright sunlight on a tablet. While the course author may intuitively think changing a font to bright red will add emphasis to a directive on a page, bright red type on a white background does not, in fact, provide enough color contrast to meet accessibility requirements. Course authors and instructors may not be expected to have a thorough knowledge of WCAG 2.0 requirements, but a familiarity with some of the more basic tenets is recommended. Formatting text so that it can easily be read by all may seem straightforward, but a knowledge of some rules is necessary to ensure accessibility. Text and background must have sufficient contrast. Unless black text is being used on a white background, a contrast check (see contrast checker available at https://contrastchecker.com) should be employed to ensure the contrast ratio is at least 4.5:1 for normal text, 3:1 for text 18-point or larger. Color alone should not be used for emphasis. A color with sufficient contrast (see above) may be used in conjunction with boldface or italics. Large blocks of boldface or italics, however, are discouraged. Line spacing should be 1.5 or more. Headings should be created using semantic markup or predefined styles in the LMS, rather than simple formatting with font size and boldface. Links should be descriptive so that their meaning is clear when "skimming" a document with a screen reader. For example, rather than "to download the Johnson article, click here," one could write "download the Johnson article" (Henry, 2018).

Visuals are an important element of Universal Design for Learning; however, extra work is required to ensure that those who cannot view an image will still be provided with all information conveyed in it. Substantive images should have descriptive alternative ("alt") text. (Unlike a photo caption, alternative text should describe exactly what is shown in the image.) Decorative images should be marked as "null" in the alt text, which will direct a screen reader to skip over it. Infographics or complex images must be described thoroughly in the page content or in a linked page or document.

Multimedia information such as videos, PowerPoint presentations, and other multimedia materials can make a course more dynamic and engaging than one presented in an all-text format. One must ensure, though, that videos should have closed captioning and downloadable transcripts. Presentations with audio should have little or no background noise (including music) as well as downloadable transcripts. Visual presentations (e.g., animation, screenshots) should have a non-visual alternative such as a document that thoroughly describes all elements of the presentation, including actions, scenery, and expressions. For more information on making your online course accessible, the complete WCAG 2.0 guidelines are available at https://www.w3.org/TR/WCAG20/.

\subsection{Teaching Presence}

Establishing an active teaching presence in an online course can easily become a secondary consideration when the focus is on content, accessibility, and student outcomes. Fortunately, there are strategies instructors can use to design learning experiences that incorporate instructor immediacy into the online learning experience. The advantages of online courses for instructors include being able to use and reuse (short) recorded lectures, pre-written discussion prompts, and selfgrading quizzes. However, instructors should intentionally build in time for direct student engagement. The instructor's personal communication is likely the most influential aspect of increasing teaching presence in online courses (Dixson, 2015). Availability is one of the most consistently appreciated qualities in online instructors (e.g., promptly replying to 
email and being accessible to students at regular, often nontraditional, times of the day). Consider online office hours that allow students to meet with the instructor in a video conference (e.g., Zoom, Skype, Google Meets, etc.) at least once during each course. Make the most of this time with guided questions to help instructors better understand student backgrounds, concerns, and feedback on course content. Video conferences (direct interaction with instructors) can significantly diminish transactional distance and help build a strong teaching presence. Instructors can take notes on students (e.g. location, background with the topic, the reason for being in the program) which is helpful when creating discussion groups and remembering key information about a student when/if it is necessary to address student needs/situations individually. Be mindful of video conferencing security options on the selected conferencing tool (e.g., password protect conferences, avoid sharing links on social media, use waiting rooms, set screen sharing capabilities, consider limiting participant abilities to annotate, lock meetings, mute participants, etc.). Use your institution instructional technology resources, ask a colleague or look for an online video training to learn more about the potential resources of each tool. Video conferences may also encourage students to disclose a need for accommodations in the course or upcoming life events that could adversely affect learner progress.

\subsection{Effective Communication}

Clear expectations are essential. Course authors and instructors can maximize the potential of student success on assignments with very clear and specific directions to guide students in communicating their knowledge. Consider the ideal final product: What do students need to be able to do to adequately demonstrate mastery of learning goals? Keep in mind the need to provide enough direction for text-based formatting to communicate assignment expectations. Taskanalyze each step and/or component of the assignment from the student's perspective. Consider starting with the "end" in mind (e.g., What are the specific components and characteristics of a desired finished product?). List the steps/procedures and detailed requirements of each component. Consider breaking up large tasks into smaller, more manageable tasks to keep students moving in the right direction at a pace that would allow them to finish as expected by given deadlines. Be sure students know exactly how, when, where and what format is required to upload final assignments. Consider sharing examples of quality work products (which do not "give away" content) with students to clarify expectations for quality final products. Developing detailed and specific rubrics gives instructors an opportunity to "out-think" students when reviewing assignment directions and grade clarifications (McKeithan et al., 2021). A thorough task-analysis of the directions and scoring criteria can help instructors to identify and correct potential submission issues related to how directions are worded (reduce the potential of poorly submitted assignments related to poorly worded expectations and/or unrealistic timelines).

Ongoing assessment and feedback are consistently linked to student success. Grade rubrics can be a critical resource for students if they are detailed with explicit explanations and point values for each required element of the assignment. Students should have access to these resources when developing their assignments, and instructors should use them to objectively assess student mastery of learning goals. Feedback related to each required component of the assignment must be aligned with the stated rubric/expectations. Instructors who regularly reteach courses can copy, paste, and recycle personal databases of feedback to students about each assignment in the course. Detailed rubrics and feedback databases can significantly reduce grading time and promote instructor presence by offering specific, objective, and fair feedback to learners (Martin \& Bolliger, 2018). Instructor expectations and feedback rubrics can be used to assess student expectations including timely submissions and connecting new learning with evidence from course materials. Table 3 includes a basic example of a rubric with embedded feedback for instructors to consider.

Table 3. Example Grade Rubric

\begin{tabular}{llll}
\hline $\begin{array}{l}\text { Required } \\
\text { Aspect }\end{array}$ & \multicolumn{1}{c}{$\begin{array}{c}\text { Full Credit } \\
(10 \text { points })\end{array}$} & \multicolumn{1}{c}{$\begin{array}{c}\text { Partial Credit } \\
(5 \text { points })\end{array}$} & \multicolumn{1}{c}{$\begin{array}{c}\text { No Credit } \\
(0 \text { points })\end{array}$} \\
\hline Initial Post & $\begin{array}{l}\text { Includes complete sentences } \\
\text { responds to all prompts; supported } \\
\text { with evidence from course } \\
\text { materials and presented as } \\
\text { informed knowledge }\end{array}$ & $\begin{array}{l}\text { Responds to at least } 1 / 2 \\
\text { the prompts; uses } \\
\text { evidence from course } \\
\text { materials }\end{array}$ & $\begin{array}{l}\text { Does not respond } \\
\text { sufficiently to the } \\
\text { prompts and support with } \\
\text { evidence from course } \\
\text { materials }\end{array}$ \\
\hline $\begin{array}{l}\text { Web Tool } \\
\text { Usage }\end{array}$ & $\begin{array}{l}\text { Includes a screenshot of the } \\
\text { associated web tool usage/post, } \\
\text { and your initial post covers all the }\end{array}$ & $\begin{array}{l}\text { Includes a screenshot of } \\
\text { the associated web tool } \\
\text { usage/post; not clearly } \\
\text { address at least } 1 / 2 \text { of } \\
\text { required prompts }\end{array}$ & $\begin{array}{l}\text { Missing screenshot of } \\
\text { associated web tool } \\
\text { usage or you do not } \\
\text { clearly address required } \\
\text { components }\end{array}$ \\
& & &
\end{tabular}


Timely feedback to students related to assessed performance can further build instructor presence in online classes. Another benefit of the online classroom is the electronic gradebook. Instructors can easily keep track of student progress and address any concerns about student progress in a timely manner (e.g., missing or late assignments or consistently unsatisfactory grades). Identifying and addressing concerns quickly can build instructor presence and minimize the potential snowball effect on future assignments. Consider developing a routine of checking the gradebook on a regular basis and create a consistent series of steps to address inadequate student progress in a manner that indicates your awareness of the problem while simultaneously offering support and suggestions to learners. Course authors and online instructors must be cognizant of the intrinsic and motivating value (power) of grades and instructor feedback on student performance (Vaessen et al., 2017). Take advantage of the electronic gradebook feature to automatically apply the late policy outlined in the rubric if students miss a submission deadline. While students must be held accountable and late, missing and poor-quality assignments can be frustrating for instructors, consider the potential negative if students believe the instructor is not willing to work with them or compromise. Instructors may consider allowing students to revise (highlight/color code corrections) and resubmit for regrading within a given timeline. Allowing students to take advantage of this option can be motivating for students to extend their own learning experiences and skills by taking the time to make needed adjustments; they may also feel more supported in their efforts to meet course objectives.

Given that the goal is student achievement and continued progress/enrollment, regular communication with students who have not submitted assignments is essential. Be cautious of the tone of the communication (Dickenson, 2017). Help students to understand you are aware of the problem, but you are a resource to help the student resolve the problem as well. Using some of the previously noted strategies such as clear, specific assignments and grade rubrics, can allow instructors to grade quickly and provide feedback in a timely manner. At the very least, giving a student a zero if an assignment is not turned in when due (along with an encouraging email) can increase the likelihood the student will not ignore the missing assignment and fall further behind in the course.

Collaboration with colleagues, student advisors, and other teachers may help identify patterns of behavior and support that were useful in other circumstances. It is important that the instructor contact the student as soon as possible or the student's academic advisor. Avoiding these difficult conversations helps no one. Keep a record of all contacts and contact attempts with students (via email or google drive) so the efforts to assist students are documented and in compliance with university policy and procedures. Table 4 offers some examples of student support messages for instructors to consider if students are not making satisfactory progress.

Table 4. Potential Student Support Messages

\begin{tabular}{ll}
\hline \multicolumn{1}{c}{ Situation } & \multicolumn{1}{c}{ Support Message } \\
\hline $\begin{array}{l}\text { Missing } \\
\text { assignment }\end{array}$ & $\begin{array}{l}\text { Dear Scholar, I am concerned that you have not yet uploaded two of the required major } \\
\text { assignments for this course. Your current GPA does not meet the required "B" average } \\
\text { needed to earn credit for this course. As you know, next Friday is the official last day of } \\
\text { classes, and the deadline to submit assignments is midnight (date here). Do you anticipate } \\
\text { you will be able to meet this requirement? I am available for a conference over the next } \\
\text { few days should you need assistance. Just text/call me at 555-545-5555. I am copying Dr. } \\
\text { Jones (advisor). Please let us know how we can help you finish these requirements and } \\
\text { move onto meeting the next milestone towards your degree; CC: advisor; send to personal } \\
\text { and school email }\end{array}$
\end{tabular}

$\begin{array}{ll}\begin{array}{l}\text { Did not } \\ \text { participate in }\end{array} & \text { This is a "friendly reminder" that the first post to the discussion forum is due by midnight } \\ \text { discussion } & \text { tonight. Please review the discussion directions and grade rubric to earn full credit on this } \\ & \text { assignment. Please contact me if you have questions or concerns. Note: Instructors can } \\ \text { modify this assignment if a student can still participate for reduced credit. Send via grade } \\ \text { feedback to prior to deadline }\end{array}$

Late assignments

This is a friendly reminder that the assignment submission deadline has passed. Please review the syllabus for information regarding late assignment submission and department policy regarding required assignments and minimum grade requirements associated with progressing onto the next course.

Assignment quality is not meeting standards and/or
While I appreciate your efforts on the submitted assignment, I encourage you to pay close attention to assignment directions and the grading rubrics when drafting and revising your written assignments. In addition, please review the professional writing expectations noted in the syllabus to ensure your writing reflects your informed knowledge rather than your 
did not follow directions opinion (even informed opinion). If you would like to use the specific feedback noted in the rubric to revise and resubmit, you can. Students can revise (each assignment once per semester), highlight changes in yellow, resubmit and email me to ask for re-grading prior to the last day of class.
Lack of quality engagement in a discussion forum
It is easy to think online discussion may not be considered a particularly meaningful task. The current set up (although not a perfect system), is designed to encourage active engagement in academic discourse among students. The ability to think deeply about important topics, apply what you know and have learned along with considering the thoughts, opinions, and experiences of others is a vital part of your education. Electronic communication is important in workplace collaboration in our world. We regularly communicate using email, texting, social media, and virtual team "rooms" for collaboration. Using electronic communication to share information and exchange ideas with others while simultaneously considering potential responses to your written communication (e.g., word choice, tone, grammar, and subject matter) is an essential skill. Although it is easy to focus on our own perspective and respond quickly (reactively) to someone with an emotional, potentially curt and/or offensive electronic response (text/email, etc.), that reactive response may inhibit the effective exchange of information or ideas as emotions can become the focus rather than resolving the issue in the best interests of the child, school, etc. Discussion prompts encourage you to respond to topics related to key concepts, share ideas, reflect on new learning, and exchange ideas. There is a significant need for more experts in the field to be able to work collaboratively with others (likely will include electronic communication). We will know more if we communicate effectively with others. The discussion boards are an opportunity to develop our skills and share experiences. Engaging with others is part of the graduate student experience. I am happy to speak with you about this format or consider ideas about how to make the discussion more effective!

The end of each assignment, unit or project, consider including a reflection question which asks students to provide feedback related to the strengths, weaknesses and relevance of the assignment or content. Require students to offer feedback on how the assignment might be improved. Instructors might also design an anonymous electronic survey to collect student feedback about the material and instructional delivery (google forms, survey monkey, etc.). Learner comments can become integral in course revision/improvements. Weekly announcements can be copied, saved, recycled, and "tweaked" by instructors who routinely teach the same course.

Engage with students on a regular basis via weekly, module/unit announcements (e.g., video, text-based, or both). An announcement can be used to outline the upcoming reading and writing assignments (including estimates of the time commitment for that week), address common misconceptions noted in previous group assessments, help learners understand the theme and relevance of upcoming tasks, or even address any seasonal activities that may impact course progress (e.g., holidays, spring break, etc.). Offering virtual office hours is another way for students to connect with an instructor and have an opportunity to ask questions and clarify expectations. Requiring individual (graded) virtual meetings can be an excellent resource to enhance instructor presence, build positive relationships with students, identify concerns and address content relevancy from the learner's perspective.

\subsection{Social Presence}

Learning is a social process, and creating a meaningful, social presence in the online classroom is an ongoing challenge for learners and instructors. However, course designers can provide opportunities and incentives which promote authentic and meaningful social interaction among learners (Bryan et al., 2018). Discussion boards are the most obvious space for relationship-building among online students. The group dynamic of face-to-face classes is not readily transferable to the online space. Instructors can task analyze all the components of a desired and meaningful discussion and explain that the online discussion is a multifaceted assignment in which students must complete several steps to earn their grade. Make it clear they are being asked to consider information from the text or course and respond to a selected prompt by a certain date. As with all assignments, expectations for discussion boards must be clear. A detailed rubric is very useful for instructors and learners. Rubrics can include requirements for discussion posts in terms of length, references to course materials, the inclusion of personal experiences, timelines, and penalties for not meeting the expectations. Instructors who have tried to keep up with how many students "responded to two peers" by randomly selecting peers from a single (lengthy) discussion thread can easily recognize the limitations of such interaction. Breaking students up into smaller groups and switching groups a few times during the semester can help to alleviate these issues (Tibi, 2018).

Be specific about all the desired components of the discussion grade. An example of a four-part discussion assignment is 
as follows: (1) Students may be asked to introduce themselves and their setting as it relates to the selected prompt. They may be required to compare ideas or identify a topic or author that most resonated with them from the readings. They should be expected to define any key concepts, explain the relevance or significance of their selection in the real world. They may be asked to integrate their own thoughts/experiences, reference the materials specifically, and pose a thoughtful question to peers which extends the conversation. They must post their initial post by a given date/time, so discussion group members have time to read and respond to their posts. (2) Once the first posts are available, group members should read and respond to all members of their small group. They should refer to the person by name, use course content as well as their own respectful thoughts and experiences to respond. (3) Once the second deadline has passed, group members should respond to each of the posts that were directed at them with the same respectful and informed perspective. (4) Finally, each learner should copy/paste the record of all their posts and responses to peers with dates/times (unless the learning management system can generate this for the instructor) and upload the documentation of their participation for grading. Asking students to upload documentation into a "discussion documentation" assignment upload can make it easier for instructors to grade.

Students can be randomly assigned to discussion groups by the online platform or groups can be purposefully created based on the instructors' knowledge of individual students. Purposefully creating groups can ensure students are exposed to a variety of viewpoints. Students can build a rapport more easily with a smaller group and potentially maintain connections after the course finishes. In discussion forums, students can personalize responses to peers by addressing peers by name, referencing comments from the peer's post, requiring learners to pose a question in their response which is designed to extend the conversation. Adding timeline requirements so students must post, respond to all group members and respond again to peers who commented on their posts can promote more active social engagement.

Giving students choice from multiple prompts, allowing them to respond with a variety of media, visuals, audio clips, etc. can help to stimulate meaningful discussion. Synchronous video discussion groups are another potential option for students which can significantly enhance social presence among peers and with the instructor. Requirements for traditional and video discussion board posts should be available before the first discussion: deadlines for initial posts and responses, the inclusion of citations to weekly readings and presentations, and inclusions of a thought-provoking question, requiring students to post their own responses before being able to view the posts of others and directed to group members to stimulate additional discussion are useful strategies. Further, instructors may be able to adjust the LMS settings so that students must post their own responses to the discussion prompt before the online platform 'allows' them to see their group members' responses. Increased personalization and collegiality of comments make the discussion boards more meaningful and promote the development of an active social learning environment (Dyer et al., 2018). 3.6.2 Adverse Events

If interventions were studied, detail all important adverse events (events with serious consequences) and/or side effects in each intervention group.

\section{Discussion}

The demand for rigorous and engaging online learning experiences is rapidly becoming an expectation of learners with a wealth of potential learning options available to them. On the other hand, new advanced technology may be considered overwhelming to faculty and students who are not proficient with their use. The research clearly notes a connection between active engagement and positive student outcomes. Online learner engagement with course content and interpersonal interactions with the instructor and other learners can increase student performance and simultaneously decrease student attrition rates (Soffer \& Cohen, 2019). Course authors and instructors must consider what they know about the content, the challenges of online instruction, as well as what they know about their learners when designing and delivering instruction. Instructors must be mindful about purposefully incorporating strategies into virtual learning environments which minimize transactional distance. Remote learning must respect how students learn, what they are learning, and the potential limitations of the online environment. Utilizing a variety of engagement strategies and student supports can help reduce potential obstacles to online instruction (e.g., isolation, procrastination, limited learning community interactions, etc.) by increasing the likelihood that the instructor can more effectively facilitate and guide students through the learning experience. The Covid-19 crisis has significantly increased the number of online students who fully expect to be engaged in meaningful learning at their school of choice. Therefore, educators (at all levels) must be reflective practitioners who consistently examine what they are teaching and how effectively they are meeting the evolving needs of students across content and settings. A well-known educational reformer identified this need more than 75 years ago, "If we teach today as we taught yesterday, we rob our children of tomorrow" (Dewey, 1944, p. 167). Technology has the potential to significantly improve the lives of learners around the world, and these changes can simultaneously offer IHEs exciting opportunities to consider what they do from a new perspective. Using technology to develop quality learning experiences by integrating strategies which enable instructors to form meaningful relationships with students and foster collaboration among students can be rewarding and beneficial for learners, instructors, institutions 
and the world. Given the recent demand to convert traditional programs to online instruction, the research knowledge base is also challenged (now more than ever) with the demand for the continuing research on how to best utilize online learning as a default mechanism in times of crisis.

\section{References}

Al Ghamdi, A. (2017). Influence of lecturer immediacy on students' learning outcomes: Evidence from a distance education program at a university in Saudi Arabia. International Journal of Information and Education Technology, 7(1), 35. https://doi.org/10.18178/ijiet.2017.7.1.838

American Psychological Association. (1972). Ethical standards of psychologists. Washington, DC: American Psychological Association.

Aronson, B. (2020, March 30). How to succeed in online classes during the COVID-19 pandemic. https://inchemistry.acs.org/content/inchemistry/en/college-life/transitioning-to-online-classes.html

Best, B., \& Conceição, S. C. O. (2017). Transactional distance dialogic interactions and student satisfaction in a multiinstitutional blended learning environment. European Journal of Open, Distance and E-Learning, 20(1), 139-153. https://doi.org/10.1515/eurodl-2017-0009

Black, S., \& Allen, J. D. (2019). Part 9: Planning instruction. The Reference Librarian, 60(2), 93-108. https://doi.org/10.1080/02763877.2019.1571469

Bledsoe, T. S., \& Simmerok, B. D. (2013). A multimedia-rich platform to enhance student engagement and learning in an online environment. Online Learning Journal, 17(4), 1-10. https://doi.org/10.24059/olj.v17i4.398

Board, U. A. (2017). Information and communication technology (ICT) standards and guidelines. Federal Register, $82(11), 1-52$.

Bryan, T. K., Lutte, R., Lee, J., O’Neil, P., Maher, C. S., \& Hoflund, A. B. (2018). When do online education technologies enhance student engagement? A case of distance education at University of Nebraska at Omaha. Journal of Public Affairs Education, 24(2), 255-273. https://doi.org/10.1080/15236803.2018.1429817

Croxton, R. A. (2014). The role of interactivity in student satisfaction and persistence in online learning. Journal of Online Learning and Teaching, 10(2), 314.

Dewey, J. (1944). Democracy and education: An introduction to the philosophy of education. Macmillan.

Dickinson, A. (2017). Communicating with the online student: The impact of e-mail tone on student performance and teacher evaluations. Journal of Educators Online, 14(2), 1-10. https://doi.org/10.9743/jeo.2017.14.2.5

Dixson, M. D. (2015). Measuring student engagement in the online course: The Online Student Engagement scale (OSE). Online Learning, 19(4). https://doi.org/10.24059/olj.v19i4.561

DuPont, J., Harff, S., Park, S., \& Linder, K. E. (2018). Marketing online degrees to adult learners: Staff, resources, and key strategies. In Leading and Managing e-Learning (pp. 321-334). Springer, Cham. https://doi.org/10.1007/978-3319-61780-0_22

Dyer, T., Aroz, J., \& Larson, E. (2018). Proximity in the online classroom: Engagement, relationships, and personalization. Journal of Instructional Research, 7(1), 108-118. https://doi.org/10.9743/jir.2018.10

Fallahi, M. (2019). Making instruction work for adult learners. In Outcome-Based Strategies for Adult Learning (pp. 111). IGI Global. https://doi.org/10.4018/978-1-5225-5712-8.ch001

Ginder, S. A., Kelly-Reid, J. E., \& Mann, F. B. (2018). Enrollment and employees in postsecondary institutions, Fall 2017; and Financial statistics and academic libraries, fiscal year 2017: First Look (Provisional Data) (NCES 2019- 021rev). U.S. Department of Education. Washington, DC: National Center for Education Statistics. http://nces.ed.gov/pubsearch

Henrie, C. R., Halverson, L. R., \& Graham, C. R. (2015). Measuring student engagement in technology-mediated learning: A review. Computers \& Education, 90, 36-53. https://doi.org/10.1016/j.compedu.2015.09.005

Henry, L. S. (2018). Introducing the web content accessibility guidelines (WCAG), including WCAG 2.0 and WCAG 2.1. Web Accessibility Initiative. https://www.w3.org/WAI/standards-guidelines/wcag/\#intro

Koslow, A., \& Piña, A. A. (2015). Using transactional distance theory to inform online instructional design. Instructional Technology, 12(10), 63-77.

Kuo, Y. C., Walker, A. E., Schroder, K. E., \& Belland, B. R. (2014). Interaction, internet self-efficacy, and self-regulated learning as predictors of student satisfaction in online education courses. The Internet and Higher Education, 20, 35- 
50. https//doi.org/10.1016/j.iheduc.2013.10.001

Linder, K. E., Fontaine-Rainen, D. L., \& Behling, K. (2015), Whose job is it? Key challenges and future directions for online accessibility in US Institutions of Higher Education. Open Learning, 30(1), 21-34. https://doi.org/10.1080/02680513.2015.1007859

Lowenthal, P., \& Hodges, C. (2015). In search of quality: Using quality matters to analyze the quality of massive, open, online courses (MOOCs). The International Review of Research in Open and Distributed Learning, 16(5). https://doi.org/10.19173/irrodl.v16i5.2348

Martin, F., \& Bolliger, D. U. (2018). Engagement matters: Student perceptions on the importance of engagement strategies in the online learning environment. Online Learning, 22(1), 205-222. https://doi.org/10.24059/olj.v22i1.1092

McKeithan, G. K., Rivera, M. O., \& Robinson, G. G. (2021). High-leverage instructional practices for students with autism and mild disabilities in traditional and remote learning settings. Global Journal of Intellectual and Developmental Disabilities, 7(3), 1-10. https://doi.org/10.19080/GJIDD.2021.07.555719

Moore, K., \& Shemberger, M. (2019). Mass communication andragogy for teaching online adult learners. Teaching Journalism \& Mass Communication, 9(1), 35-40. http://www.aejmc.us/spig/journal

Reese, S. A. (2015). Online learning environments in higher education: Connectivism vs. dissociation. Education and Information Technologies, 20(3), 579-588. https://doi.org/10.1007/s10639-013-9303-7

Sammel, A., Weir, K., \& Klopper, C. (2014). The pedagogical implications of implementing new technologies to enhance student engagement and learning outcomes. Creative Education, 5(02), 104-113. https://doi.org/10.4236/ce.2014.52017

Soffer, T., \& Cohen, A. (2019). Students' engagement characteristics predict success and completion of online courses. Journal of Computer Assisted Learning, 35(3), 378-389. https://doi.org/10.1111/jcal.12340

Stopa, M. M. (2017). Pedagogical practices to develop community in undergraduate online learning: The affordances of technology, a mixed method study. [Doctoral dissertation, North Carolina State University].

Svinicki, M. D., \& McKeachie, W. J. (2013). McKeachie's teaching tips: Strategies, research, and theory for college and university teachers. Houghton-Mifflin.

Tibi, M. H. (2018). Computer science students' attitudes towards the use of structured and unstructured discussion forums in online courses. Online Learning, 22, 93-106. https://doi.org/10.24059/olj.v22i1.995

Vaessen, B. E., van den Beemt, A., van de Watering, G., van Meeuwen, L. W., Lemmens, L., \& den Brok, P. (2017). Students' perception of frequent assessments and its relation to motivation and grades in a statistics course: a pilot study. Assessment \& Evaluation in Higher Education, 42(6), 872-886.

https://doi.org/10.1080/02602938.2016.1204532

Vlachopoulos, D., \& Makri, A. (2019). Online communication and interaction in distance higher education: A framework study of good practice. International Review of Education, 65(4), 605-632. https://doi.org/10.1007/s11159-01909792-3

Weidlich, J., \& Bastiaens, T. (2018). Technology matters - the impact of transactional distance on satisfaction in online distance learning. International Review of Research in Open and Distributed Learning, 19(3), 222-242. https://doi.org/10.19173/irrodl.v19i3.3417

World Wide Web Consortium. (2019). Web content accessibility guidelines (WCAG) 2 requirements. Web Accessibility Initiative. https://www.w3.org/WAI/WCAG21/quickref/

Wynants, S., \& Dennis, J. (2018). Professional development in an online context: Opportunities and challenges from the voices of college faculty. Journal of Educators Online, 15(1). https://doi.org/ 10.9743/jeo2018.15.1.2

Yılmaz, R., \& Keser, H. (2017). The impact of interactive environment and metacognitive support on academic achievement and transactional distance in online learning. Journal of Educational Computing Research, 55(1), 95122. https://doi.org/10.1177/0735633116656453

\section{Copyrights}

Copyright for this article is retained by the author(s), with first publication rights granted to the journal.

This is an open-access article distributed under the terms and conditions of the Creative Commons Attribution license which permits unrestricted use, distribution, and reproduction in any medium, provided the original work is properly cited. 